\title{
Limites e falência do corpo: 0 acesso ao tratamento de mulheres usuárias de crack em um CAPSad do Rio de Janeiro
}

\section{Body limits and failure: the access to treatment of female crack users at a CAPSad from Rio de Janeiro}

\author{
Taís Veronica Cardoso Vernaglia ${ }^{a}$ \\ (D) https://orcid.org/0000-0003-3391-7301 \\ E-mail: tais.vernagliaळunirio.br \\ Marcelo Santos $\mathrm{Cruz}^{\mathrm{b}}$ \\ (D) https://orcid.org/0000-0003-0057-2095 \\ E-mail: marcelosantoscruzœipub.ufrj.br

\section{Simone Ouvinha Peres ${ }^{c}$ \\ (D) https://orcid.org/0000-0001-7352-8664 \\ E-mail: simoneoperesळgmail.com}

a Universidade Federal do Estado do Rio de Janeiro. Escola de Enfermagem Alfredo Pinto. Departamento de Enfermagem Médico-Cirúrgico. Rio de Janeiro, RJ, Brasil.

buniversidade Federal do Rio de Janeiro. Instituto de Psiquiatria. Programa de Pós-Graduação em Saúde Mental. Rio de Janeiro, RJ, Brasil.

'Universidade Federal do Rio de Janeiro. Instituto de Psicologia. Departamento de Psicologia Social. Rio de Janeiro, RJ, Brasil.

\section{Resumo}

O abuso de crack evidencia um problema de saúde pública complexo a ser enfrentado. Neste contexto, o consumo pelas mulheres as coloca em situação de maior vulnerabilidade. 0 artigo tem como objetivos identificar e descrever as motivações para o acesso ao tratamento de mulheres usuárias de crack em um Centro de Atenção Psicossocial (CAPSad), voltado ao atendimento de pessoas com problemas com o álcool e outras drogas. Trata-se de um estudo qualitativo, feito através de observação participante e realização de nove entrevistas em profundidade com mulheres usuárias de crack, submetidos à análise temática. Os resultados indicam a presença do corpo como o argumento usado pelas mulheres para justificar a procura pelo atendimento no CAPSad. As questões ligadas ao corpo, tais como, as vivências de cansaço físico, dor, sono, emagrecimento, esgotamento, medo de morrer e da violência das ruas, direcionaram as usuárias para o tratamento. Muitas delas sentiam essa necessidade em decorrência do abuso do crack e precisavam de ajuda dos profissionais de saúde, por meio do pedido de medicação e acolhimento noturno. Assim, é fundamental reconhecer o uso do corpo como ferramenta de acesso ao tratamento por parte das mulheres usuárias de crack.

Palavras-chave: Assistência ao Paciente; Vulnerabilidade Social; Saúde Mental; Cocaína Crack; Identidade de Gênero.

\section{Correspondência}




\section{Introdução}

Crack abuse evidences a complex public health problem to be confronted. In this context, crack use by women exposes them to vulnerable situations. This article aims at identifying and describing the motivations to access to treatment of female crack users in a Psychosocial Care Center (CAPSad) for people with alcohol and other drug problems. This is a qualitative study that used participant observation and in-depth interviews with nine female crack users examined by thematic analysis. The results indicate that the body is used as a reason to justify the seek for treatment. Body issues directed them to treatment, such as the experiences of physical tiredness, pain, sleep deprivation, weight loss, exhaustion, fear of dying and the violence on the streets. Many of them felt these needs due to crack abuse and showed that by requesting medication and night care from health professionals' team. In conclusion, body must be understood as an important tool used by female crack users on access to treatment.

Keywords: Patient Care; Social Vulnerability; Mental Health; Crack Cocaine; Gender Identity.
As repercussões sociais e de saúde pública em torno do uso do crack são percebidas diretamente nas estratégias voltadas para o cuidado no âmbito do sistema público de saúde brasileiro, o Sistema Único de Saúde (SUS). No país, esse cenário evidencia um problema de saúde pública complexo a ser enfrentado.

Estimativas nacionais e internacionais caracterizam a magnitude do problema do uso/abuso do crack. No Reino Unido, aumentou a quantidade de adolescentes, menores de 16 anos, presos por suspeita de fornecimento de crack, cocaína e heroína (UNODC 2018). 0 uso do crack está associado a diversos agravos na saúde clínica e mental dos usuários, como: infecções respiratórias, doenças sexualmente transmissíveis, depressão e comportamento suicida (UNODC, 2018). Além disso, o crack tem sido uma droga de escolha importante dentre o grupo de usuários de múltiplas drogas, que deve ser levado em consideração no tratamento dessa população (Eastwood; Strang; Marsden, 2017; Heidebretch; MacLeod; Dawkins, 2018).

Nesse contexto, percebe-se que as mulheres estão mais sujeitas às iniquidades sociais e de saúde, o que as tornam mais vulneráveis ao uso de drogas, dentre elas o crack. A exemplo disso, estimativas comprovam que os problemas associados ao uso de drogas por mulheres em situação de rua são maiores quando comparados aos dos homens que se encontram nas mesmas condições (UNODC, 2018). Como agravante, as usuárias de crack estão submetidas a julgamentos sociais preconceituosos e estigmatizantes que repercutem nas diversas situações de vulnerabilidades das mulheres e obstaculizam o acesso aos tratamentos no Centro de Atenção Psicossocial (CAPSad) (Monteiro; Villela, 2013).

No Brasil, estudos sobre temas correlatos a mulheres, álcool e drogas mostram importantes processos de discriminação social que dão origem a diferentes formas de violências. Essas violências se ligam ao gênero, mas também à raça, à etnia e à sexualidade como processos sociais conectados a estruturas mais amplas de poder e dominação, que repercutem nas diversas situações de vulnerabilidade no que se refere à saúde (Monteiro; Villela, 2013). 
O uso do crack entre as mulheres, portanto, não costuma ser bem aceito socialmente, gerando o estigma, o preconceito e a sua relação com a discriminação, bem como alguns dos principais sofrimentos em saúde, doenças, segregações e violências dirigidas às usuárias (Fertig et al., 2016; Parker, 2013).

A presença de mulheres usuárias de crack nas cenas de uso frequentadas majoritariamente por homens reforça as desigualdades, expondo-as a diferentes problemas relacionados a uma persistente hierarquia de gênero que organiza e institui as relações (Fertig et al., 2016). Nesses espaços, percebe-se a manutenção e a reprodução de relações históricas de dominação entre homens e mulheres - aos homens é "permitido" o crime, às mulheres, a prostituição (Romanini; Roso, 2013).

A ausência de usuárias nas unidades de saúde do CAPSad (Malta et al., 2008) deve ser problematizada face à histórica predominância da atenção à saúde sexual e reprodutiva das mulheres nos serviços de Atenção Básica à Saúde, no âmbito da prevenção, assistência e promoção. 0 domínio saúde reprodutiva tem maior participação na assistência às mulheres em correlação aos demais problemas de saúde, sendo as mulheres mais assíduas do que os homens nas unidades de saúde pública (Barata, 2009; Botton; Cúnico; Strey, 2017). Inversamente, quando o problema é o de álcool e drogas, as mulheres se encontram mais ausentes do que os homens nas unidades de saúde.

Em particular, leva-se em conta a hipótese da discriminação das usuárias como uma das razões das dificuldades de elas chegarem aos CAPSad, resultante do sentimento de vergonha e do receio de serem maltratadas como usuárias de droga, ligado aos escrúpulos sociais relacionados à identidade cultural de "mulheres cracudas". Juntase a isso a cultura fortemente masculinizada das cenas de uso e as práticas discriminatórias que se reproduzem quanto às mulheres usuárias, devendo ser compreendidas e combatidas, principalmente no âmbito da assistência à saúde. Nesse sentido, os objetivos deste estudo foram descrever e analisar como se constitui o acesso ao tratamento de mulheres usuárias de crack em uma unidade CAPSad.

\section{Métodos}

Este é um estudo qualitativo realizado com nove mulheres usuárias de crack que acessaram um Centro de Atenção Psicossocial para pessoas com problemas com o álcool e outras drogas (CAPSad III), localizado na cidade do Rio de Janeiro.

Utilizou-se como estratégia a observação participante e as entrevistas em profundidade, durante o período de sete meses de trabalho de campo. 0 uso dessas ferramentas metodológicas proporcionou a imersão no cotidiano da unidade, de modo a permitir: conhecer as usuárias, a dinâmica de atendimento da unidade, as suas rotinas, os obstáculos e os desafios nas questões relativas ao acesso ao tratamento.

As nove mulheres incluídas no estudo correspondem ao total de usuárias que tinham o crack como droga preferencial e acessaram ao serviço durante o trabalho de campo. Foram excluídas duas mulheres: uma que estava bacílifera (contaminação por bacilo de Koch) e outra que foi contatada na cena de uso do território e não compareceu ao CAPSad conforme convite feito para a realização da entrevista. Após o consentimento para a participação no estudo, os relatos concedidos pelas mulheres foram gravados e seus nomes codificados e substituídos por outros fictícios, para que o sigilo das informações fosse mantido.

Após a leitura sistemática e exaustiva das entrevistas e dos diários de campo, o material coletado foi incluso no banco de dados da pesquisa com vistas a definir os eixos temáticos analíticos. Utilizou-se um software de análise de dados qualitativos - Nvivo versão 820 para suporte e organização do material. Em seguida, as informações obtidas foram submetidas às etapas da análise de temática (Minayo, 2014). Esta pesquisa foi enviada e aprovada pelo Comitê de Ética e Pesquisa da Universidade Federal do Estado do Rio de Janeiro (CAAE: 51280515.7.0000.5263; Parecer: 1.526.402).

\section{Resultados e discussão}

Em relação aos motivos das mulheres usuárias de crack buscarem atendimento no CAPSad III, o corpo que precisa ser cuidado foi identificado como a principal razão a partir de dois elementos: os limites 
do corpo falido e o corpo estigmatizado. Além disso, elas recorrem ao acesso ao tratamento a partir do pedido de medicalização para conter e lidar com o abuso do crack e do acolhimento noturno como medida de proteção.

\section{o corpo falido e estigmatizado no acesso ao tratamento}

Constatou-se, nas falas das mulheres, que o acesso ao tratamento se deu nas circunstâncias dos limites impostos por um corpo doente. Para elas, esse limite apareceu a partir da radicalidade do consumo do crack e que, na questão que tange ao acesso ao tratamento, foi evidenciado como tema principal, em razão de um corpo que precisava ser cuidado. Observou-se nas narrativas que elas identificavam os sinais de esgotamento físico e que a decisão de acesso se relacionava ao sentimento desse esgotamento, representado através da suplica por comida, uma cama para dormir e um lugar para tomar banho.

Em relação às consequências do uso do crack, foram relatados sintomas corporais como efeito do uso descontrolado do crack: "assim o dia inteiro, a noite toda, até passar mal" (Gicélia, 33 anos). Esses efeitos presentes nas muitas narrativas eram descritos como devastadores: "Tava saindo sangue pela boca, pelo nariz, pelas fezes, quase morrendo mesmo. Eu não conseguia andar, ficava caindo, horrivel" (Renata, 34 anos).

Em uma lógica mais ampla, entende-se que o acesso ao tratamento das mulheres se deu quando a satisfação proporcionada pelo uso do crack foi substituída pelo esgotamento dos seus corpos. As usuárias descreveram um momento chamado de "fase da vida do ou tudo ou nada", que exemplifica o sentido que Denise (3o anos), uma das entrevistadas, atribui à sua própria trajetória com o uso do crack em relação ao seu momento atual.

Percebe-se, neste caso, que a satisfação produzida pela droga já não era mais tão recompensadora. Rosane, por exemplo, expressou a motivação em procurar o CAPSad da seguinte forma: "O que me motiva é minha própria vida eu já tô saturada de só usar droga [...] Porque nesse mundo, nesse espacinho que só tem viciado ali, você não tem amizade [...] você não é ninguém, ninguém nem te enxerga" (Rosane, zo anos).
Muitas das narrativas dessas mulheres expressaram que seus corpos, suas vidas quase atingiram muitas vezes os limites entre a vida e a morte: "Agora, o meu uso, se vocês querem saber, é extremamente suicida" (Almerinda, 61 anos).

Para entendermos essa perspectiva, podemos partir do conceito de corpo apresentado por Le Breton (2017), sendo ele sempre um operador de socialização. É através dele que se evidenciam os estatutos de desigualdade, em especial, aqueles relativos a homens e mulheres e seus respectivos processos de individualização.

Nota-se que, para as mulheres usuárias de crack, o corpo se opõe à exclusão, na medida em que é apresentado como um fator motivador do acesso ao tratamento, sendo, portanto, uma ferramenta de inclusão social. Le Breton (2017, p. 30) ao falar sobre o corpo o descreve como marcado pelos limites da pessoa, "onde começa e acaba a presença do indivíduo".

Um segundo ponto que demarcou os motivos que as levaram a buscarem tratamento foi o estigma sobre a mulher e seu corpo. Constatou-se que o estigma é um dos terríveis efeitos negativos do uso do crack. Assim, repetiram-se, nos relatos das entrevistadas, as falas relativas ao corpo feminino que sofria alterações, dentre elas, a falta de apetite e o consequente emagrecimento.

Ribeiro, Sanchez e Nappo (2010) afirmam que, entre as mulheres usuárias de crack, o emagrecimento é o problema mais relatado sobre seu corpo. As autoras referem que "os fatores que contribuem para o emagrecimento são: supressão do apetite, inquietação psicomotora e longas caminhadas em busca por crack nos momentos de fissura" (Ribeiro; Sanchez; Nappo, 2010, p. 213).

Os efeitos devastadores do crack foram observados nas narrativas das entrevistadas por meio da observação delas sobre a mudança da imagem de seus corpos. Observou-se, nos relatos proferidos em tons de lamento e pesar, o quanto a imagem da mulher usuária de crack era arrebatadora: “A minha madrinha me levou lá onde ela ficava [referindo-se ao local onde sua mãe, que é usuária de crack, estava]. Minha mãe tinha o maior corpão e a última vez que eu vi ela tava muito, muito magra. Eu chorei, falei pra ela: volta pra casa" (Daniele, 18 anos). 
As marcas do crack em seus corpos desgastavam de modo impressionante a imagem que possuíam de si. As entrevistadas sabiam que a sua imagem era de um corpo abandonado que não era mais cuidado, mas era atacado pelas drogas e isso lhes impactava. Elas sabiam que seu corpo estava totalmente fora dos padrões sociais: "Aí, no segundo dia, eu acordava igual um bicho pra usar” (Renata, 34 anos).

Uma ocorrência fundamental e marcante na vida do sujeito estigmatizado é o fato dele se tornar desacreditável principalmente pelos que o conhecem, quando passa a ser tratado como "insano" (Goffman, 1988). Nas falas ouvidas, prevalecia o medo das pessoas notarem a diferença nos seus corpos e, consequentemente, delas serem rotuladas e estigmatizadas: "uma mulher de 61 anos sendo drogada", contempla a fala de um filho sobre sua mãe (Almerinda, 61 anos, comentando com pesar a crítica feita por seu filho).

É enorme a importância de entender o quanto uma mulher como Almerinda pode se prejudicar ou se beneficiar da reação dos outros em relação ao fato de ser usuária de crack aos 61 anos. Já dissemos anteriormente que quando uma usuária pensa que deve recorrer a um serviço de saúde é porque possui um conceito prévio sobre seu estado, seus limites, seus riscos, principalmente sobre o que o campo da saúde e os profissionais de saúde podem fazer por ela. Esse conceito, seja ele qual for, não só determina a maneira e o tipo de ajuda que escolhe, mas também influencia todo o transcurso do tratamento que ela aceitará e estará disposta a fazer (Chiozza, 1987).

Com linguagem clara, Almerinda relatou a magnitude dos efeitos do preconceito que recaem sobre ela e o sofrimento de ser considerada a "vovó do crack" (apelido de Almerinda na cena de uso). A "enfermidade" das usuárias não pode ser contemplada como uma coisa banal que irrompe, pois, apesar de tudo e de não parecer, o olhar dos outros repercute nos afetos, nas emoções e pode dificultar o acesso aos serviços. Convém examinar os preconceitos vigentes no consenso social que podem essencialmente limitar a aproximação das usuárias com os dispositivos de saúde. É preciso reconhecer a presença da angústia do estigma que recai entre as usuárias, evidenciado na fala de Sônia: “Aí eu ia pra rua, dava uma volta, as pessoas começaram a notar minha diferença. Emagreci, eu não penteava mais os meus cabelos" (Sônia, 31 anos).

Estigma e discriminação são padrões de interação social que trazem como consequência desrespeito e violência e, tratando-se de saúde, repercutem nas situações de vulnerabilidade social (Ayres, 2009). Eles são conceitos definidos por relações políticas e de poder, pautadas nas desigualdades e exclusão social (Ayres, 2009). No caso das mulheres usuárias de crack, o corpo feminino estigmatizado era o que sofria alterações, mudava de forma, era notado por outros e, por isso, excluído.

\section{A medicação com oferta fundamental no acesso ao tratamento}

As mulheres entrevistadas vão ao CAPSad em busca da medicação que possa lhe ajudar a controlar e reduzir o uso abusivo do crack. Os remédios são solicitados também com o objetivo de diminuir a ansiedade proveniente da restrição do uso abusivo do crack.

Nos relatos das entrevistadas apareceu especialmente o pedido do "remédio" para o “restabelecimento da normalidade". Portanto, a norma referia-se a uma determinada lógica de um "ideal" de que o "remédio" funcionaria para o seu caso e que ele se relacionava diretamente com seu histórico de tratamento.

Todas faziam uso de psicotrópicos e entendiam que a medicação era um recurso para lidarem com as emoções e o desejo de usar o crack, ou seja, uma ferramenta de autocontrole. Nos depoimentos, é possível perceber que suas expectativas eram de um domínio sobre seus pensamentos, suas reações e suas emoções: "Queria usar a droga todo dia. Agora tá sumindo essa vontade. Tô tomando o remédio direito. Tô dormindo" (Gicélia, 33 anos).

A medicação se tornou um importante recurso para permanecerem sem usar o crack: "Eu pedia haldol pra os outros. Eu queria dar um tempo, mas eu não conseguia" (Sônia, 31 anos). Observou-se que para elas era fundamental estarem em um estado de sedação: "Eu tô com uma medicação muito forte, forte mesmo. [...] Quando eu tô dopada, eu não penso em droga. Eu durmo, eu como, eu durmo. Não tenho tempo pra pensar em droga" (Denise, 30 anos). 
Entre o crack, que lhes produzia um estado de "pancação", e o remédio, um estado de "dopação", elas escolhiam o último: "É bem melhor assim, nesse estado de dopação, que eu sinto que estou dopada [efeito produzido pela medicação], do que o estado de pancação [efeito produzido pelo crack], que eu sinto que tô pancada" (Gicélia, 33 anos).

Observou-se que a promessa de que teriam o remédio disponível na unidade foi uma ferramenta de acesso ao tratamento. Também, notou-se que esse foi um recurso utilizado por alguns profissionais na descrição sobre como se constitui o tratamento para lidar com os efeitos do crack. Daniele e Rosane, entrevistadas, falaram sobre como a equipe do Consultório na Rua valeu-se desse modo para apresentar o tipo de tratamento disponível no CAPSad III. Nesse sentido, as mulheres relataram que suas expectativas do acesso eram que encontrariam o remédio como forma de tratamento.

Denise explicou que, quando se sentia cansada e sabia que teria de pegar dois ônibus para chegar ao CAPSad, enfrentava a "preguiça”, porque, caso não o fizesse, ficaria sem seus remédios: "eu tenho que vir buscar os remédios que são semanais” (Denise, 30 anos). Para as mulheres, a promessa dos remédios é tão importante quanto as chamadas "conversas".

As relações simbólicas com os medicamentos são evidentes em diversas instâncias sociais e de saúde. Os estudos de Peter Conrad nos ajudam a entender o processo de construção social a respeito da prática da medicalização. $\mathrm{O}$ autor fala que nos últimos 50 anos houve um aumento do impacto social dos conceitos da medicina e, consequentemente, um crescente número de produtos destinados ao cuidado em saúde invadindo os mercados. Para o referido autor, essa é a forma que usamos para tratar dos problemas em termos de doença e distúrbio. Ele afirma que esses conceitos são definidos a partir de um quadro médico e tratados a partir de uma intervenção médica (Conrad, 2007).

A medicalização ocorre nos mais variados planos que incluem a medicalização do desvio, sendo exemplos: o alcoolismo, os transtornos mentais, a dependência de opiáceos, os transtornos alimentares, as diferenças sexuais e de gênero, a disfunção sexual, as dificuldades de aprendizagem e o abuso sexual e infantil (Conrad, 2007). Peter
Conrad (2007) atenta para o fato de que é preciso preocupar-se quando a medicalização transforma aspectos da vida cotidiana em patologias, estreitando o alcance do que é considerado aceitável.

As mulheres partiam da premissa de que no CAPSad III "tem médico e remédio" (Daniele, 18 anos). Sobre isso, Boltanski (1989, p. 20) afirma: "a doença, assim definida, está então inteiramente qualificada pela sua relação, em primeiro lugar como um sinal e, em segundo lugar, com um remédio". Para ele, existe uma espécie de nosografia popular que define as doenças e o objeto que abandonamos nas mãos do especialista é o nosso corpo (Boltanski, 1989).

Sabe-se que o processo de acesso ao tratamento das pessoas em situação de rua se dá, principalmente, a partir das unidades que estão diretamente vinculadas ao trabalho no território. Sobre esse aspecto, alguns autores percebem que na Estratégia Saúde da Família a consulta médica de saúde mental está muito relacionada com a questão da farmacologia, ou seja, o ato da renovação da receita dos psicofármacos (Mielke; Olschowsky, 2011). As referidas autoras enfatizam que se deve romper com a estrutura de medicalizar e prescrever, valorizando a construção e espaços de produção da saúde (Mielke; Olschowsky, 2011).

Percebe-se que os saberes biológicos se constituem socialmente como referência para essas questões. Para Sarti (2010), esse é um campo difícil, já que é marcado por relações de poder instituídas pelo lugar social que detém o saber em nossa sociedade.

Para essas mulheres, a medicalização estava associada à possibilidade de frearem seus impulsos e emoções, um instrumento de contenção do desejo de usar o crack. Nesse caso, aproxima-se da nomeação que Ferreira (2007, p. 292) faz sobre a função ou estatuto de operador social do corpo: "onde o social se torna possível e onde, consequentemente, se revela a eficácia do social sobre o indivíduo". Na tentativa das mulheres em apreender o social e reproduzir a ordem do mundo era preciso conter, sob quaisquer circunstâncias, o abuso do crack. Assim fica a questão: como romper com a estrutura de medicalizar e prescrever, valorizando-se a construção de espaços de produção da saúde diante da demanda das usuárias? 


\section{0 acolhimento noturno como facilitador do acesso das mulheres ao CAPSad}

Percebeu-se que, quando as mulheres chegavam ao acolhimento noturno, seus corpos estavam em alto grau de esgotamento físico e padeciam de cuidados, de atenção e atendimentos de diversas ordens. Para lidar com esgotamento dessa ordem, era preciso um lugar de cuidado de forma intensiva. As sensações em seus corpos eram tão intensas e urgentes que elas queriam se sentir protegidas nas 24 horas do dia. Sobre isso, a fala da Renata (34 anos), que chegou ao CAPS após ter passado muitos meses na cena de uso, é expressiva: "Porque eu fico sendo acompanhada 24 horas pelas pessoas, né? Se eu tiver com alguma crise de abstinência, quiser algum remédio. $\varepsilon$ um trabalho diferente, né? É melhor".

Além disso, o pedido pelo acolhimento se relacionava com a intensidade dos sintomas percebidos por elas. Gicélia (33 anos), quando procurou o acolhimento noturno, lamentou os efeitos do crack: "É horrivel. Eu tava com dor de cabeça, segunda feira. Eu cheguei com muita dor de cabeça, não dormi direito, vomitei. Passo muito mal por causa da droga".

Nesse contexto, as usuárias queriam descansar seus corpos. Por isso, os leitos eram o local de abrigo onde elas entendiam que poderiam obter resposta imediata ao sofrimento provocado pelo abuso do crack. Nesse sentido, nota-se que a descrição do acolhimento se relacionava a um dispositivo clínico para atender as demandas do corpo.

Os leitos do acolhimento noturno também foram descritos como um lugar de abrigamento que lhes conferia segurança nas situações em que sentiram suas vidas em risco. Assim, para elas, o acolhimento noturno transformava-se também numa resposta estratégica ao medo das ruas, à violência, às humilhações e ao pânico eminente de morrer. Compreender esse significado do acolhimento noturno é, inevitavelmente, incluí-lo num contexto que o ressignifica, de modo que o doente, o corpo e a doença possam ser acolhidos. O pedido por acolhimento noturno é uma forma de linguagem, um sentido que irrompe, uma parte indissociável do pedido de ajuda (Chiozza, 1987).

A história que se oculta por trás do pedido de acolhimento noturno, o subentendido é o pedido das mulheres por contenção na unidade de saúde como forma de se livrar da dura realidade das ruas a qual temiam. A ideia de estar livre e sem proteção nas ruas amedrontava algumas mulheres, como afirmou Denise (30 anos): "falaram que a UA [Unidade de Acolhimento] você pode ficar livre para fazer o que quiser. Se for assim, eu vou querer continuar aqui porque eu tenho pavor de sair na rua sozinha".

Isso também se relacionava com as situações de violência às quais algumas mulheres estavam submetidas. A história de Gicélia, registrada em diário de campo, testemunha que ela recorria ao acolhimento noturno porque se sentia desprotegida na sua casa. Além disso, as mulheres esperavam que, a partir do tratamento recebido, elas pudessem se manter longe do crack: "Tô me acostumando a ficar abstinente. Não tô sentindo tanta falta da droga igual eu sentia [...] Me ajudou muito a ficar longe das drogas e voltar para casa sem droga" (Gicélia, 33 anos).

É importante perceber que algumas mulheres recorreram ao acolhimento noturno porque elas dizem ser esse o modo encontrado para não cederem ao desejo de usar o crack. Poderíamos dizer que, a exemplo de Teresinha (33 anos), muitas usuárias gostariam de ficar "confinadas" num serviço de saúde para receberem atenção e carinho: "Muita atenção, muito carinho, conversar com a pessoa que usa, dá atenção [...], brincar, se puder trancar a porta, tranca pra não poder sair. Se tentar arrombar, tu abre, conversa".

Entretanto, a experiência mostra que existe um paradoxo entre o tempo de permanência no leito definido pela Portaria $n^{0} 130$ e a necessidade apresentada pelas mulheres. De acordo com a Portaria, o período que podem permanecer no acolhimento é de no máximo 14 dias, o que não parece ser suficiente. Gicélia, durante seu acolhimento noturno, vislumbrava ficar mais tempo e contava, com certo ar de empolgação, que sua mãe entraria com um pedido de internação compulsória para que passasse mais tempo no CAPSad III - "quero tá aqui um mês!" (Gicélia, 33 anos).

Renata, em um dos seus acolhimentos noturnos, também falou que seu pai entraria com um pedido de internação compulsória: "Agora descobriram que meu pai tá na justiça pra conseguir uma internação compulsória. Aí, ele me colocou aqui, eu tô aqui 
pela compulsória, mas eu vou ficar aqui por tempo indeterminado ainda, não sei quando vou sair" (Renata, 34 anos). Rosane, que não havia passado pelo acolhimento noturno, tinha uma expectativa de se "internarpor pelo menos seis meses" (Rosane, 30 anos).

As histórias que mostramos tentam evidenciar e esclarecer uma questão importante, um problema indissociável relacionado ao tratamento das usuárias de crack. A experiência empírica nos ensina que o acolhimento noturno é uma ferramenta de cuidado que se coaduna com os preceitos da reforma psiquiátrica (Pereira et al., 2017). A Portaria $\mathrm{n}^{0} 130$, de 26 de janeiro de 2012, confere destaque à questão dos leitos de acolhimento noturno, através do incentivo financeiro à implantação dos CAPS III (Brasil, 2012). A referida Portaria deixa claro que estes devem ser destinados ao abrigamento noturno com base nas necessidades de desintoxicação e reabilitação psicossocial, como a necessidade de observação, repouso e proteção, manejo de conflito, dentre outros (Brasil, 2012).

Poderíamos dizer que o fato desse recurso responder de maneira imediata às necessidades básicas das usuárias, tais como: sono, alimentação, banho, descanso etc., ele se relaciona com um modo fundamental de compreender de modo empírico a necessidade delas. 0 uso dos leitos de atenção integral em um CAPSad III tem como objetivos: "prevenção à recaída, redução de danos, proteção em condições de riscos sociais e de extrema vulnerabilidade, tratamento de abstinências leves e abrigamento em caso de fissuras intensas" (Brasil, 2010, p. 9) e isso basta para evidenciar uma necessidade prática.

Diversos autores discorrem sobre as situações de vulnerabilidade social e de saúde nas quais se encontram os usuários de crack associadas ao esgotamento descrito pelas mulheres incluídas neste estudo.

A vulnerabilidade para as usuárias reside em: estarem sujas, com vestes rasgadas, higiene precária, magreza e problemas aparente de pele, que iam desde rachaduras e feridas aparentemente infectadas (Zeferino et al., 2017). Além dessas condições, não se pode ignorar outros aspectos contidos na ideia de vulnerabilidade, por exemplo: o comportamento sexual arriscado, a overdose, o emagrecimento e a insônia (Ribeiro; Sanchez; Nappo, 2010). Do mesmo modo, existem condições como: "exposição às variações climáticas, condições insalubres de moradia e de alimentação, e ações de repressão por parte de políticas de segurança pública, que afetam negativamente a condição de saúde dos indivíduos em situação de rua" (Hallais; Barros, 2015, p. 1501).

Entende-se que, dentre as estruturas necessárias para a ampliação do acesso ao tratamento dos usuários de crack, é importante a implantação de pontos de acolhimento. Esses pontos deveriam ofertar a possibilidade de alimentação, descanso, atividades de promoção da saúde e redução de danos (Brasil, 2010). Ficou claro que as mulheres incluídas no estudo desconheciam essas estruturas e demandavam do CAPSad III essa oferta de cuidado.

Alguns autores justificam a busca pela internação prolongada como medida de proteção. O usuário de crack, em geral, mantém um padrão compulsivo de uso, associado com alguns prejuízos, como atividades ilícitas, violência, prostituição e problemas judiciais. Com isso, a internação prolongada seria a forma de tratamento preferencialmente procurada por familiares e pelo próprio usuário; embora, além desta, existem outras modalidades de tratamento (Picoli, 2013). A busca pelo cuidado hospitalar foi mencionada por outros autores nos casos de overdose. A morte seria um risco inerente ao consumo de crack, mas que, quando evitada, permite a manutenção da dependência por muitos anos (Ribeiro; Sanchez; Nappo, 2010).

Por fim, em relação ao pedido da interrupção do uso do crack, isso se repete em outras pesquisas. Pedrosa et al. (2016) destaca que os participantes do seu estudo demonstravam um desejo de sair da situação em que se encontravam, e que associavam isso à necessidade de se manterem abstinentes para terem possibilidade de recomeçar.

É certo que alguns autores criticaram o fato de o CAPSad embasar suas práticas em um modelo biomédico, o qual visa a "cura" através da abstinência (Paula et al., 2014). Para Romanini e Roso (2013, p. 493), a abstinência é um conceito que está relacionado a própria concepção de quem são os usuários de crack: "se concebermos o usuário de drogas como dependente químico, como uma vítima da substância, somente a abstinência e a interdição do contato com a droga podem produzir efeitos terapêuticos". 


\section{Considerações finais}

Neste estudo, da perspectiva concreta das mulheres, o desejo de ter um corpo que pudesse ser cuidado constitui uma importante motivação para buscar ajuda por parte das usuárias.

Sob a égide de um corpo falido e estigmatizado, com sinais de deterioração e esgotamento, sentindo na "pele" o limite da vida imposto pela radicalidade do consumo do crack, elas, apesar de tudo, esperam ajuda do CAPSad para seus problemas.

A percepção feminina do estigma que recai sobre elas deriva dos sinais perceptíveis em seus corpos por conta do abuso do crack. Nas experiências vividas, as mulheres consideravam grave a sua situação, visto a partir da sensação física e subjetiva de fragilização e deterioração do corpo. Isso era assinalado através do desejo de querer retomar o corpo anterior, ganhar peso, melhorar a aparência e sentir-se mais interessante.

Demarcamos que existe uma questão que retém nosso maior interesse: as usuárias tinham a expectativa de abrigamento e medicalização. Nesse ponto, é preciso dizer que os profissionais de certo modo avaliavam como a medicação poderia responder às mazelas dos seus corpos. Dessa forma, enquanto em outros dispositivos de saúde as mulheres vivenciavam como realidade a dificuldade de acesso à terapia medicamentosa, elas vislumbravam que no CAPSad teriam suas demandas respondidas. No discurso das mulheres, a medicalização foi apresentada como uma ferramenta de contenção. $O$ pedido feito por elas foi de que a medicação pudesse lhes proporcionar um estado de autocontrole, para lidarem com o abuso do crack.

Além da perspectiva medicamentosa, as mulheres esperavam encontrar no CAPSad uma estrutura que lhes provesse o descanso e a proteção para um corpo que dava sinais de esgotamento. Assim, elas pediam pelo acolhimento noturno, que responderia ao medo das situações de risco em que eram submetidas na rua e as que eram impostas pelo próprio abuso da substância.

Por fim, com base no que foi exposto, é fundamental reconhecer os elementos que caracterizam o acesso ao tratamento das mulheres usuárias de crack. 0 CAPSad precisa estar preparado para lidar de forma imediata com as consequências geradas pelos corpos adoecidos e falidos dessas mulheres. É importante reconhecer que o estigma é uma peça simbólica essencial que deve ser vista como uma parte que integra o problema do acesso e acolhimento das usuárias.

\section{Referências}

AYRES, J. R. C. M. Organização das ações de atenção à saúde: modelos e práticas. Saúde e Sociedade, São Paulo, v. 18, p. 11-23, 2009. Suplemento 2. Disponível em: <https://bit. ly/32vXvvY>. Acesso em: 23 out. 2018.

BARATA, R. B. Relações de gênero e saúde: desigualdade ou discriminação? In: BARATA, R. B. (Org.). Como e por que as desigualdades sociais fazem mal à saúde. Rio de Janeiro: Editora Fiocruz, 2009. p. 73-94. (Coleção Temas em Saúde). Disponível em: <https://bit.ly/3n92NYo>. Acesso em: 18 jan. 2016.

BOLTANSKI, L. As classes sociais e o corpo. 3. ed. Rio de Janeiro: Graal, 1989.

BOTTON, A.; CÚNICO, S. D.; STREY, M. N. Diferenças de gênero no acesso aos serviços de saúde: problematizações necessárias. Mudanças: Psicologia da Saúde, v. 25, n. 1, p. 67-72, 2017. Disponível em: <https://bit.ly/3v4gvxS >. Acesso em: 18 out. 2017.

BRASIL. Ministério da Saúde. Abordagens terapêuticas a usuários de cocaína/crack no Sistema Único de Saúde: texto preliminar destinado à consulta pública. Brasília, DF, 2010. Disponível em: <https://bit.ly/3akqfw4>. Acesso em: 22 jun. 2018.

BRASIL. Ministério da Saúde. Portaria nº 130, de 26 de janeiro de 2012. Redefine o Centro de Atenção Psicossocial de Álcool e outras Drogas $24 \mathrm{~h}$ (CAPS AD III) e os respectivos incentivos financeiros. Diário Oficial da União, Brasília, DF, 2012. Disponível em: <https://bit.ly/3x5lSPg>. Acesso em: 22 jun. 2018.

CHIOZZA, L. Por que adoecemos? A história que se oculta no corpo. Campinas: Papirus, 1987. 
CONRAD, P. The medicalization of society: on the transformation of human conditions into treatable disorders. Baltimore: Johns Hopkins University Press, 2007.

EASTWOOD, B.; STRANG, J.; MARSDEN, J. Effectiveness of treatment for opioid use disorder: a national, five-year, prospective, observational study in England. Drug and Alcohol Dependence, Limerick, v. 176, n. 1, p. 139-147, 2017. Disponível em: <https:// bit.ly/3syRVn4>. Acesso em: 23 abr. 2021.

FERREIRA, V. S. Política do corpo e política de vida: a tatuagem e o body piercing como expressão corporal de uma ética da dissidência. Etnográfica, Lisboa, v. 11, n. 2, p. 291-326, 2007. Disponível em: <https://bit.ly/32qkZme>. Acesso em: 29 out. 2018.

FERTIG, A. et al. Mulheres usuárias de crack: conhecendo suas histórias de vida. Escola Anna Nery, Rio de Janeiro, v. 20, n. 2, p. 310-316, 2016. Disponível em: <https://bit.ly/2QBrXSL>. Acesso em: 16 jul. 2018.

GOFFMAN, E. Estigma: notas sobre a manipulação da identidade deteriorada. 4. ed. Rio de Janeiro: LTC, 1988.

HALLAIS, J. A. S.; BARROS, N. F. Consultório na rua: visibilidades, invisibilidades e hipervisibilidade. Caderno de Saúde Pública, Rio de Janeiro, v. 31, n. 7, p. 1497-1504, 2015. Disponível em: <https://bit. ly/3tBChss $>$. Acesso em: 29 out. 2018.

HEIDEBRETCH, F.; MACLEOD, M. B.; DAWKINS, L. Predictors of heroin abstinence in opiate substitution therapy in heroin-only users and dual users of heroin and crack. Addictive Behaviors, Oxford, v. 77, p. 210-216, 2018. Disponível em: <https://bit.ly/3sMhOAf>. Acesso em: 23 abr. 2021.

LE BRETON, D. A sociologia do corpo. 6. ed. Petrópolis: Vozes, 2017.

MALTA, M. et al. HIV/AIDS risk among female sex workers who use crack in Southern Brazil. Revista de Saúde Pública, São Paulo, v. 42, n. 5, p. 830-837, 2008. Disponível em: 〈https://bit.ly/3mZNSiC>. Acesso em:16 jul. 2017.

MIELKE, F. B.; OLSCHOWSKY, A. Ações de saúde mental na estratégia saúde da família e as tecnologias em saúde. Escola Anna Nery, Rio de Janeiro, v. 15, n. 4, p. 762-768, 2011. Disponível em: <https://bit.ly/2QeegoA>. Acesso em: 29 out. 2018.

MINAYO, M. C. S. O desafio do conhecimento: pesquisa qualitativa em saúde. 14. ed. Rio de Janeiro: Hucitec, 2014.

MONTEIRO, S.; VILLELA, W. (Org.). Estigma e saúde. Rio de Janeiro: Editora Fiocruz, 2013.

PARKER, R. Interseções entre estigma, preconceito e discriminação na saúde pública mundial. In: MONTEIRO, S.; VILLELA, W. (Org.). Estigma e saúde. Rio de Janeiro: Editora Fiocruz, 2013. p. 25-46.

PAULA, M. L. et al. Usuário de crack em situações de tratamento: experiências, significados e sentidos. Saúde e Sociedade, São Paulo, v. 23, n. 1, p. 118-130, 2014. Disponível em: <https://bit. ly/3dxRW6Q>. Acesso em: 23 out. 2018.

PEDROSA, S. M. et al. A trajetória da dependência do crack: percepções de pessoas em tratamento. Revista Brasileira de Enfermagem, Brasília, DF, v. 69, n. 5, p. 956-963, 2016. Disponível em: <https:// bit.ly/3dyroDM>. Acesso em:15 maio 2018.

PEREIRA, M. O. et al. Qual é a tônica da política de drogas brasileira: ressocialização ou internamento? Escola Anna Nery, Rio de Janeiro, v. 21, n. 3, e20170044, 2017. Disponível em: <https://bit.ly/3tx9Egh>. Acesso em: 15 out. 2018. PICOLI, C. M. C. Adesão de usuários de crack ao tratamento num CAPS I do interior do Rio Grande do Sul. 2013. Dissertação (Mestrado em Psicologia) - Universidade Federal de Santa Catarina, Florianópolis, 2013.

RIBEIRO, L. A.; SANCHEZ, Z. M.; NAPPO, S. A. Estratégias desenvolvidas por usuários de crack para lidar com os riscos decorrentes do consumo da droga. Jornal Brasileiro de Psiquiatria, Rio de Janeiro, v. 59, n. 3, p. 210-218, 2010. Disponível em: <https://bit.ly/zaooYUQ>. Acesso em: 23 out. 2018.

ROMANINI, M.; ROSO, A. Midiatização da cultura, criminalização e patologização dos usuários de crack: discursos e políticas. Temas em Psicologia, Ribeirão Preto, v. 21, n. 2, p. 483-497, 2013. Disponível em: <https://bit.ly/3x7BNN4>. Acesso em: 23 out. 2018. 
SARTI, C. Corpo e doença no trânsito de saberes. Revista Brasileira de Ciências Sociais, São Paulo, v. 25, n. 74, p. 77-9o, 2010. Disponível em: <https:// bit.ly/2REFo4O>. Acesso em: 29 out. 2018.

UNODC - UNITED NATIONS OFFICE ON DRUGS AND CRIME. World drug report 2018: Report No. E.18.XI.9. Vienna: United Nations Publication, 2018.

UNODC - UNITED NATIONS OFFICE ON DRUGS AND CRIME. Wor DRUGS AND
AGE Drugs and associated issues among young people and older people: Report No. E.18.XI.9. Vienna: United Nations Publication, 2018.

ZEFERINO, M. T. et al. Semelhanças e contrastes nos padrões de uso de crack em Santa Catarina, Brasil: capital vs Meio Oeste. Ciência \& Saúde Coletiva, Rio de Janeiro, v. 22, n. 1, p. 97-106, 2017.

Disponível em: <https://bit.ly/3gpxK8S>. Acesso em: 23 out. 2018.

\section{Contribuições dos autores}

Vernaglia participou na concepção, delineamento, análise e interpretação dos dados e da redação do artigo. Cruz participou da discussão dos resultados, da revisão crítica e aprovação da versão final do trabalho. Peres participou da discussão dos resultados, da revisão crítica e aprovação da versão final do trabalho

Recebido: $11 / 10 / 2019$

Aprovado: 12/02/2021 